\title{
An Empirical Analysis on the Influencing Factors of Economic Growth in Anhui Province
}

\author{
Jialing Ren, Zejiong Zhou, , \\ ${ }^{1}$ School of Finance, Anhui University of Finance and Economics, Bengbu, Anhui, China \\ ${ }^{2}$ School of Economics, Anhui University of Finance and Economics, Bengbu, Anhui, China \\ ${ }^{*}$ Corresponding author email: aczzj123456@163.com
}

\begin{abstract}
This paper selects the per capita consumption expenditure, the whole society's fixed asset investment, fiscal expenditure and the turnover of technology contracts from 2000 to 2019 as the explanatory variables and GDP as the explanatory variables, and uses the regression analysis method to make a quantitative analysis on the factors of economic growth in Anhui Province. The results show that the GDP of Anhui Province is greatly affected by per capita consumption expenditure and technology contract turnover on the premise of excluding the autocorrelation between variables. Finally, it puts forward some targeted policy suggestions for the high-quality economic development of Anhui Province.
\end{abstract}

Keywords: Economic growth, OLS regression analysis, Stepwise regression, White test.

\section{Introduction}

Since the 18th CPC National Congress, Anhui's economy has maintained sustained growth, the coordinated development of primary, secondary and tertiary industries, the living standards of residents have been significantly improved, and urban and rural residents share economic development. In the process of development, Anhui's economy pays more and more attention to the role of science and technology, fiscal expenditure, consumer demand and fixed asset investment in promoting economic development, and remarkable achievements have been made in economic development. In the past five years, the GDP growth rate of Anhui Province has been ahead of the national GDP growth rate, and the industrial structure has been continuously optimized, changing from "two three one" to "three two one". From the perspective of fiscal revenue and expenditure, the fiscal selfsufficiency rate has been around $45 \%$ in the past five years, but it shows a downward trend on the whole, and the fiscal self-sufficiency rate is relatively general.

On February 20, 2021, the 14th five year plan for national economic and social development of Anhui Province and the outline of long-term objectives for 2035 issued by Anhui provincial government pointed out that the province should optimize the regional economic layout, promote the coordinated development of "One Circle and Five Regions" and promote economic growth. In the opinions of the general office of Anhui Provincial People's Government on promoting online economic development issued by the provincial government office, it also highlights the tasks of strengthening the construction of new infrastructure, promoting the accelerated development of the province's online economy, expanding new economic growth points and cultivating new drivers of high-quality development.

Scholars at home and abroad have conducted extensive research on the impact of economic growth and achieved rich results. Lucass (1961) and Romer (1990) introduced human capital elements into Solow model and believed that human capital should be considered as an independent element to consider its impact on economic growth. Moreover, they conducted empirical research on the influencing factors of economic growth. The empirical results show that human capital is the endogenous driving force of long-term economic growth [1] [2]. Ni Hongfu and Ji Chen (2020) analyzed the consumption structure of residents in China and the United States from 1971 to 2017 by using the input-output table. By comparing the proportion of consumption in the three major industries of the two countries, they found that the impact of consumption on China's tertiary industry is increasing. This conclusion shows that consumption is playing an important role in China's economic growth [3]. Liu Hongjie (2008) used VAR model to study the relationship between fiscal revenue and GDP. The results show that fiscal revenue has a positive impact on GDP [4]. The research of Bai Junhong (2017) and Zhang Kuan (2020) shows that the science and technology expenditure behavior of local governments and the allocation of science and technology innovation resources have an obvious effect on the growth of local GDP $[5,6]$. The research of Yan Dongbin (2020) shows that scientific and technological progress in Beijing, Tianjin and Hebei has an obvious role in promoting economic development [7]. Zhao Jianguo and Guan Wen (2021) believe that scientific and technological innovation is becoming a new yardstick of local development, and the requirements for scientific and technological innovation ability in the new development stage are increasing [8]. Li Xiang et al. (2019) believe that scientific and technological innovation has a significant impact on economic growth [9].

Compared with other developed provinces, the foundation of economic development in Anhui Province is still relatively weak. Analyzing the influencing factors of economic growth in Anhui Province and taking targeted development measures have certain practical significance for Anhui economic growth. Therefore, this paper uses the econometric model method to empirically analyze the influencing factors of economic growth in Anhui Province, and puts forward countermeasures and suggestions. 


\section{Variable Selection and Model Establishment}

\subsection{Variable Selection}

(1) Explained variable. Economic growth usually refers to the continuous increase of a country's per capita output (or per capita income) over a long time span. Gross output is usually measured by gross domestic product (GDP), which can reflect the economic development scale of a country or region. Here, GDP is taken as the explanatory variable of the study, expressed by Y.

(2) Explanatory variables. Based on the research results of Yan Dongsheng and other scholars (2021), this paper selects explanatory variables from four dimensions: consumption level, capital investment, fiscal expenditure and scientific and technological innovation [10]. (1) Consumption level. Consumption is the engine driving economic growth. As the final demand, consumer demand plays a direct and final decisive role in economic growth. (2) Capital investment. Capital is an important factor affecting the long-term economic growth of various provinces and regions in China. After controlling the convergence effect, policy and location of regional growth, the relationship between capital and economic growth is still significant. (3) Financial expenditure. As one of the main measures for the government to affect the macro-economy, fiscal expenditure is an important source of funds to achieve economic growth and plays an important role in promoting economic development [11]. (4) Scientific and technological innovation. Science and technology is the primary productive force, and innovation is the first driving force leading development. The innovation and development of science and technology and the transformation of scientific and technological achievements are important driving forces for economic growth. Scientific and technological progress plays a very important role in economic growth. It is reflected in enhancing the vitality of enterprises, driving employment, improving the competitiveness of enterprises and even the rise of the competitiveness of the whole society $[12,13]$.

Since Anhui Province was affected by the epidemic in 2020 , the data in 2020 were excluded. According to the collected statistical data from 2000 to 2019, take the GDP (Y) of Anhui Province as the measure of economic development; The consumption factor is measured by per capita consumption expenditure $\left(\mathrm{X}_{1}\right)$; Capital investment is measured by total investment in fixed assets $\left(\mathrm{X}_{2}\right)$; Measure financial factors with financial expenditure $\left(\mathrm{X}_{3}\right)$; The turnover of technology contract $\left(\mathrm{X}_{4}\right)$ is used to measure the factors of science and technology.

\subsection{Model Setting}

GDP can be expressed as a function of consumption level, capital investment, fiscal revenue and expenditure and scientific and technological innovation. By observing the data, the explained variable GDP and the four explanatory variables are treated by logarithm [14], that is, the model expression is:

$$
\begin{gathered}
\ln Y_{t}=\alpha+\beta_{1} \ln X_{1}+\beta_{2} \ln X_{2}+\beta_{3} \ln X_{3}+\beta_{4} \ln X_{4}+ \\
u_{i}, i=1,2,3,4
\end{gathered}
$$

Where, Y represents GDP (100 million yuan), X1 represents per capita consumption expenditure (yuan), X2 represents fixed asset investment (100 million yuan), $\mathrm{X}_{3}$ represents financial expenditure (10000 yuan), $\mathrm{X}_{4}$ represents the turnover of technical contract (10000 yuan), $\mu_{\mathrm{i}}$ stands for random disturbance term. Through the regression analysis of the model, the changing relationship between the above four explanatory variables and economic growth is obtained.

\section{Empirical Results and Analysis}

\subsection{Model Parameter Estimation}

Use Eviews software and least square method to carry out linear regression on the collected data. The following model can be obtained from the estimation results:

$$
\begin{gathered}
\ln Y=-3.0724+1.0949 \ln X_{1}-0.0186 \ln X_{2}+ \\
0.1955 \ln X_{3}-0.0386 \ln X_{4}
\end{gathered}
$$

$$
\begin{aligned}
& \begin{array}{llll}
(1.4695) & (0.3264) & (0.0971) & (0.1251)
\end{array} \\
& \mathrm{t}=(-2.0908)(3.3539) \quad(-0.1913) \quad(1.5629) \\
& \mathrm{R}^{2}=0.9975 \quad \bar{R}^{2}=0.9968 \quad \mathrm{~F}=1480.065
\end{aligned}
$$

\subsection{Model Test}

\subsubsection{Economic Significance Test}

By estimating the obtained parameters, the economic significance test can be carried out. $\alpha=-3.0724$, which means that Anhui's GDP decreased by $3.0724 \%$ when other variables remained unchanged, which is not in line with the law of economic development. $\beta_{1}=1.0949$, which means that when other variables remain unchanged, per capita consumption expenditure increases by $1 \%$, GDP increases by $1.0949 \%$. On the contrary, the reduction of $1.0949 \%$ is in line with economic reality. $\beta_{2}=-0.0186$, which means that when other variables remain unchanged, GDP decreases by $0.0186 \%$ for every $1 \%$ increase in total investment in fixed assets. On the contrary, an increase of $0.0186 \%$ is not in line with the economic reality. $\beta_{3}=0.1955$, which means that when other variables remain unchanged, GDP increases by $0.1955 \%$ for every $1 \%$ increase in fiscal expenditure. On the contrary, a decrease of $0.1955 \%$ is in line with economic reality. $\beta_{4}=-$ 0.0386 , which means that when other variables remain unchanged, GDP will decrease by $0.0386 \%$ for every $1 \%$ increase in the turnover of technology contract. On the contrary, an increase of $0.0386 \%$ is not in line with the economic reality.

To sum up, the model does not meet the economic significance, the economic significance test fails, and there may be serious multicollinearity.

\subsubsection{Goodness of Fit Test}

The closer the value of the sample determination coefficient $\left(\mathrm{R}^{2}\right)$ is to 1 , the better the fitting degree of the regression line to the observed value. On the contrary, the closer the value of $\mathrm{R}^{2}$ is to 0 , the worse the fitting degree of the regression line to the observed value. From the parameter estimation results, the sample determination coefficient is 0.9975 , indicating that its goodness of fit is high.

Because the explanatory variables are multivariate, the adjusted goodness of fit is used to eliminate the influence of explanatory variables on goodness of fit. Adjusted $R^{2}=0.9968$, so its fitting degree is good.

\subsection{Econometric Test}

\subsubsection{Multicollinearity Test}

The correlation analysis between variables is carried out, and the results are shown in Table 1: 
Table 1. Distribution of correlation coefficient

\begin{tabular}{|c|c|c|c|c|c|}
\hline $\mathrm{c}$ & $\ln \mathrm{l}$ & $\ln X_{1}$ & $\ln X_{2}$ & $\ln X_{3}$ & $\ln X_{4}$ \\
\hline $\ln \mathrm{Y}$ & 1.0000 & 0.9983 & 0.9920 & 0.9941 & 0.9946 \\
\hline $\ln X_{1}$ & 0.9983 & 1.0000 & 0.9906 & 0.9921 & 0.9972 \\
\hline $\ln X_{2}$ & 0.9920 & 0.9906 & 1.0000 & 0.9959 & 0.9839 \\
\hline $\ln X_{3}$ & 0.9941 & 0.9921 & 0.9959 & 1.0000 & 0.9866 \\
\hline $\ln X_{4}$ & 0.9946 & 0.9972 & 0.9839 & 0.9866 & 1.0000 \\
\hline
\end{tabular}

It can be seen from the correlation coefficient matrix that the correlation coefficients between explanatory variables are more than 0.98 , that is, the explanatory variables are highly correlated.

\subsubsection{Treatment of Multicollinearity By Stepwise Regression}

(1) The basic univariate regression equation is established. According to the correlation coefficient, Anhui's GDP is most closely related to per capita consumption expenditure (X1). Therefore, the following univariate regression equation is established $[15,16]$ :

$$
\ln Y=\alpha+\beta \ln X_{1}+\varepsilon
$$

(2) Gradually introduce other explanatory variables to determine the most suitable multiple regression equation. Other explanatory variables are gradually introduced for regression analysis. The results are shown in Table 2:

Table 2. Stepwise regression results

\begin{tabular}{|c|c|c|c|c|c|c|}
\hline Regression equation & $\mathrm{X}_{1}$ & $\mathrm{X}_{2}$ & $\mathrm{X}_{3}$ & $\mathrm{X}_{4}$ & $\mathrm{R}^{2}$ & $\bar{R}^{2}$ \\
\hline $\ln Y=f\left(\ln X_{1}\right)$ & $\begin{array}{l}1.2956 \\
(72.17)\end{array}$ & & & & 0.9966 & 0.9964 \\
\hline $\ln \mathrm{Y}=\mathrm{f}\left(\ln \mathrm{X}_{1}, \ln \mathrm{X}_{2}\right)$ & $1.0872(8.67)$ & $0.1019(1.68)$ & & & 0.9970 & 0.9967 \\
\hline $\ln \mathrm{Y}=\mathrm{f}\left(\ln \mathrm{X}_{1}, \ln \mathrm{X}_{3}\right)$ & $\begin{array}{c}0.9890 \\
(7.82) \\
\end{array}$ & & $0.1851(2.44)$ & & 0.9975 & 0.9972 \\
\hline $\ln \mathrm{Y}=\mathrm{f}\left(\ln \mathrm{X}_{1}, \ln \mathrm{X}_{4}\right)$ & $\begin{array}{l}1.5101 \\
(6.23) \\
\end{array}$ & & & $-0.0973(-0.89)$ & 0.9967 & 0.9963 \\
\hline $\ln \mathrm{Y}=\mathrm{f}\left(\ln \mathrm{X}_{1}, \ln \mathrm{X}_{2}, \ln \mathrm{X}_{3}\right)$ & $0.9921(7.41)$ & $\begin{array}{c}-0.0090 \\
(-0.10)\end{array}$ & $0.1944(1.60)$ & & 0.9975 & 0.9970 \\
\hline $\ln \mathrm{Y}=\mathrm{f}\left(\ln \mathrm{X}_{1}, \ln \mathrm{X}_{2}, \ln \mathrm{X}_{4}\right)$ & $1.1783(3.50)$ & $0.0941(1.38)$ & & $-0.0340(-0.2933)$ & 0.9971 & 0.9965 \\
\hline $\ln \mathrm{Y}=\mathrm{f}\left(\ln \mathrm{X}_{1}, \ln \mathrm{X}_{3}, \ln \mathrm{X}_{4}\right)$ & $\begin{array}{l}1.0730 \\
(3.62) \\
\end{array}$ & & $\begin{array}{l}0.1777 \\
(2.19) \\
\end{array}$ & $\begin{array}{c}-0.0329 \\
(-0.32) \\
\end{array}$ & 0.9975 & 0.9970 \\
\hline
\end{tabular}

According to the above table, the best multiple regression model is as follows

$$
Y=-2.624503+0.989036 \ln X_{1}+0.185066 \ln X_{3}
$$

The results show that the GDP of Anhui Province is greatly affected by per capita consumption expenditure $\left(\mathrm{X}_{1}\right)$ and fiscal expenditure $\left(\mathrm{X}_{3}\right)$.

\subsubsection{Heteroscedasticity Test}

White test is used to judge whether there is heteroscedasticity in the model, that is, at a given significance level $(\alpha)$, compare $n R^{2}$ and $\chi_{\alpha}^{2}(\mathrm{p})$. If $n R^{2}<\chi_{\alpha}^{2}(\mathrm{p})$, there is no heteroscedasticity in the model, otherwise there is $[17,18]$.

White test results show that given the significance level $\alpha=$ $0.05, n R^{2}=9.433<\chi_{\alpha}^{2}(\mathrm{p})$, so there is no heteroscedasticity in the model.

\subsubsection{Autocorrelation Test}

(1) DW inspection method. It is known that $\mathrm{n}$ is the number of data samples and $\mathrm{k}$ is the number of influencing factors of independent variables. In given $\alpha=0.05, n=20, k=2$, check the $\mathrm{D}-\mathrm{W}$ statistical table, and get $\mathrm{dL}=1.10, \mathrm{dU}=1.54$. It can be seen from $\mathrm{DW}=1.2166$ that $\mathrm{DW}=1.2166<\mathrm{dL}$, so the model has correlation [19].

(2) Partial correlation coefficient test method. With theoretical knowledge, it can be seen that the model has autocorrelation when the number of partial phase relations exceeds the dotted line. Because the straight square of partial correlation coefficients in phase 2 and phase 3 exceeds the dotted line, it is judged that the model has second-order and third-order positive autocorrelation through this test.

\subsubsection{The Generalized Difference Method Is Used to Correct the Model Autocorrelation [20]:}

Through data processing, we can see that $\mathrm{DW}=1.83>\mathrm{dU}=1.54$.

Then the partial correlation coefficient test is carried out for the modified model. The positive and posterior partial correlation coefficient test chart shows that there is no secondorder and third-order sequence correlation in the model. Therefore, the model has eliminated the influence of sequence correlation, and the regression equation between economic growth and explanatory variables can be obtained.

$$
\begin{gathered}
\ln Y=-2.5829+0.9454 \ln \mathrm{X}_{1}+0.2056 \ln \mathrm{X}_{3}+ \\
{[\operatorname{AR}(2)=-0.0976, \operatorname{AR}(3)=-0.7939]}
\end{gathered}
$$

$$
\begin{aligned}
& \mathrm{t}=(10.88424)(4.048687)(-0.277589)(-2.355918) \\
& \mathrm{R}^{2}=0.99839 \quad \bar{R}^{2}=0.99796 \quad \mathrm{DW}=1.827158
\end{aligned}
$$

According to the above model, GDP and per capita consumption expenditure are closely related to the turnover of technology contracts. When Anhui's per capita consumption expenditure increased by $1 \%$, Anhui's GDP increased by $0.9454 \%$. When fiscal expenditure increases by $1 \%$, GDP increases by $0.2056 \%$.

\section{Conclusion Analysis and Policy Recommendations}

\subsection{Main Conclusions}

(1) The pulling effect of consumer demand on the economy. Consumer demand is the factor with the largest share and the smallest fluctuation among the four demand factors. It is an important pillar and the most important component of the economy. Consumption plays an absolute role in promoting 
the economy, and consumption promotes economic development. Consumption not only increases the social demand for economy, but also drives the circulation of funds. Consumption can stimulate the market economy, provide more employment opportunities and further promote social and economic development.

(2) Science and technology is the primary productive force, and innovation is the first driving force leading development. Investment in science and technology is one of the main driving forces of economic growth and the source of vitality of economic development. Increasing investment in science and technology, promoting scientific and technological innovation and accelerating the transformation of scientific and technological achievements can greatly improve labor efficiency and production efficiency. Especially in the current Internet + social era, economic competition is actually competition in science and technology.

(3) The whole society's fixed asset investment and fiscal expenditure also contribute greatly to economic growth. Investment in fixed assets is an important driving force of economic growth. It plays a leading role in economic operation and drives economic growth with its multiplier effect. Fiscal expenditure is an effective means to improve economic efficiency and an important means of macroeconomic regulation and control. Using financial means to regulate the economy can promote the smooth operation of the economy, further promote the prosperity of the market economy, and play a great role in economic development.

\subsection{Policy Suggestion}

(1) Consumption continues to play the role of "ballast stone" in economic operation. Residents' consumption is becoming an important driving force for economic growth. We should give full play to the driving role of consumption in economic development and promote the transformation and upgrading of consumption structure. Increase production, expand employment, increase residents' income, improve people's living standards and expand domestic demand. Reasonably allocate the proportion of primary, secondary and tertiary industries, pay attention to accelerating the development of the tertiary industry, including tourism and service industry, attract foreign demand, expand domestic and foreign consumption demand, achieve internal and external linkage, and improve the pulling effect of consumption on economic growth.

(2) Scientific and technological innovation plays a significant leading role in economic and social development. Fully understand the importance of scientific and technological innovation to economic and social development, increase investment and expenditure in the field of scientific and technological innovation, and speed up the transformation of scientific and technological achievements. We should rely on scientific and technological support to lead the new type of industry, agricultural modernization and hightech industrialization, rely on scientific and technological innovation, accelerate the transformation of scientific and technological achievements into real productive forces, and promote the rapid and healthy development of the city's economy. Cultivate the main body of scientific and technological innovation and improve the independent innovation ability of enterprises. Build a scientific and technological innovation platform and create a carrier for the combination of industry, University and research. We will promote industrial transformation and upgrading, promote the industrialization of high and new technologies, and use high and new technologies to transform and enhance traditional advantageous industries. Make use of Anhui's local characteristic resource advantages, promote the transformation and upgrading of advantageous resource industries, and strive to develop strategic emerging industries.

(3) Fiscal expenditure plays an important role in macrocontrol of local economic development and is an important condition to ensure the good development of local economy. We should combine the basic characteristics of the forward development of the local economy and the actual situation of the development of each city and county, give full play to the financial function to the greatest extent, appropriately adjust the relevant fiscal policies, and ensure the rapid and stable development of the local economy. Increase investment in resource conservation and environmental protection, accelerate industrial transformation and upgrading, and create a green industry. Support the development of small and medium-sized enterprises and promote the economic development of the whole region. Increase the implementation of preferential policies for agriculture, increase rural construction funds and promote the construction of new countryside. Strengthen infrastructure construction and improve urban and rural living environment. Realize the fine management of Finance and promote the development of county economy.

(4) The level of asset investment is a decisive factor in promoting economic growth and upgrading. Give play to the role of fixed asset investment in economic growth, increase the investment in fixed assets, make up for the bottleneck of Anhui's weak economic development foundation, improve the allocation efficiency of resources and accelerate industrial development. Continuously adopt advanced technology and equipment, establish emerging departments, further adjust the regional distribution of economic structure and productivity, enhance economic strength, strengthen the construction of hard power in Anhui, strengthen the consolidation and improvement of industrial foundation, enhance the driving force of economic growth, and create material conditions for improving people's material and cultural life.

\section{References}

[1] Schultz T W. Inverstment in Human Capital[J]. American Economic Review,1961,51(5):1-17.

[2] Romer P M. Endogenous Technological Change[J]. NBER working paper, 1990,98((5):71-102.

[3] Ni Hongfu, Ji Cheng. Changes and trends of Chinese residents' Consumption Structure -- an analysis based on Sino US inputoutput table [J]. Consumer economy, 2020,36 (1): 3-12.

[4] Liu Hongjie. Quantitative research on the relationship between fiscal revenue and economic growth in China: 1978-2006 econometric analysis based on VAR model [J]. Journal of Hebei Economic and trade, 2008 (06): 5-9.

[5] Bai Junhong, Dai Wei. The impact of fiscal decentralization on local government science and technology investment [J]. Statistical research, 2017, (3): 97-106.

[6] Zhang Kuan, Huang Lingyun .Government's innovation preference and regional innovation ability: did it come true or did it backfire? [J]. Financial research, 2020, (4): 66-82.

[7] Yan Dongbin. An empirical study on the relationship between scientific and technological innovation and economic growth: 
a case study of Beijing Tianjin Yidi city group [J]. Statistics and decision making, 2020,36 (2): 114-116.

[8] Zhao Jianguo, Guan Wen. Fiscal decentralization, competition for attracting investment and the level of scientific and technological Innovation -- a study based on the innovation incentive framework of local government [J]. Research on financial issues, 2021 (3): 1-15.

[9] Li Xiang, Deng Feng. Scientific and technological innovation, industrial structure upgrading and economic growth [J]. Scientific research management, 2019.40 (3): 84-93.

[10] Yan Dongsheng, Wang Yue, Sun Wei, Li Pingxing. Comparative study on driving factors of regional economic growth and spatial spillover effect [J]. Geographical research, 2021,40 (11): 3137-3153.

[11] Bian Yuanchao, Bai Junhong ."Competition for growth" and "competition for innovation" -- a new explanation of the impact of fiscal decentralization on technological innovation [J]. Financial research, 2017, (10): 43-53.

[12] He Lingyun, Ma Qingshan. The impact of fiscal decentralization on Urban Innovation -- from the perspective of local government competition [J]. economic and management research, 2020, (10): 132-144.

[13] He Yanling, Li Ni. Competition for Innovation: a new local government competition mechanism [J]. Journal of Wuhan University, 2017, (1): 87-96.

[14] Zhou Juanmei. Interactive relationship between scientific and technological innovation and industrial transformation of resource-based cities [J]. Productivity research, 2007 (10): 100101

[15] Deng Guoguo, Gong Qinlin. Research on the impact of innovation drive on the transformation efficiency of resourcebased cities [J]. Journal of Yunnan University of Finance and economics, 2018,34 (6): 86-95.

[16] Li Gang, Zhang. Shuqing Measurement of urban contraction level and analysis of influencing factors in Anhui Province [J]. Journal of Anhui Jianzhu University, 2019,27 (5): 62-70,85.

[17] Zhao Wei. "One belt, one road" comprehensive evaluation of the development level of inland open economy in Xi'an under the background $[\mathrm{J}]$. Journal of Weinan Teachers University, 2020,35 (9): 56-63.

[18] Qiu Yanping, Zhang Jifeng. Construction of evaluation index system for the development level of open economy in Lianyungang [J]. Journal of Huaihai Institute of Technology (HUMANITIES AND SOCIAL SCIENCES), 2017,15 (10): 90-94.

[19] Cao Xiaojun. Analysis on the operating performance of listed banks in China -- Based on principal component analysis, factor analysis and cluster analysis [J]. Journal of Suzhou University, 2016,31 (7): 25-29.

[20] Yue Xingcheng, Wang Wuyi. Study on the choice of advantageous industries in the development of open economy in Anhui Province [J]. Journal of Changchun University of Technology (SOCIAL SCIENCE EDITION), 2019,32 (4): 122-127. 